\title{
Climatic changes in the abundance of anchovy in the Southeast Pacific ocean
}

\author{
Irma Martyn, Yaroslav Petrov*, Sergey Stepanov, and Artem Sidorenko
}

Russian State Hydrometeorological University, Voronezhskaya Street, 79, 192007 St. Petersburg, Russian Federation

\begin{abstract}
The article discusses the issue of the relationship between climate change and the productivity of oceanic ecosystems. The data on the course of the number of commercial populations in the productive zone of the ocean are analyzed. Comparison of data on climate fluctuations and populations of commercial fish over a period of 16 years, which will reveal the conjugation of climate fluctuations and fish productivity. On the basis of the results obtained, a model is proposed for predicting the abundance of a commercial species for several years, depending on the climate. The results obtained provide an answer to the question of whether long-term fluctuations in the abundance of commercial species are influenced by the climate or large-scale fishing.
\end{abstract}

\section{Introduction}

Over the years of fishing, it has been noticed that the abundance and catches of mass commercial fish are subject to significant long-term fluctuations [1].

The ups and downs in fisheries have significant economic and social.

According to the Food and Agriculture Organization, the Southeastern Pacific Ocean region is designated as fishing area 87 (Fig. 1). This fishing area is divided into subareas: northern, central and southern (Fig. 2) [2].

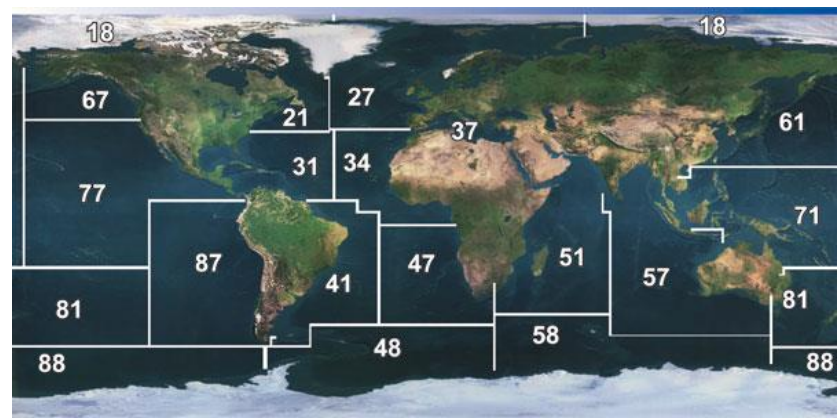

Fig. 1. Fishing areas of the World Ocean

\footnotetext{
*Corresponding author: yaroslav.petrov025@gmail.com
} 


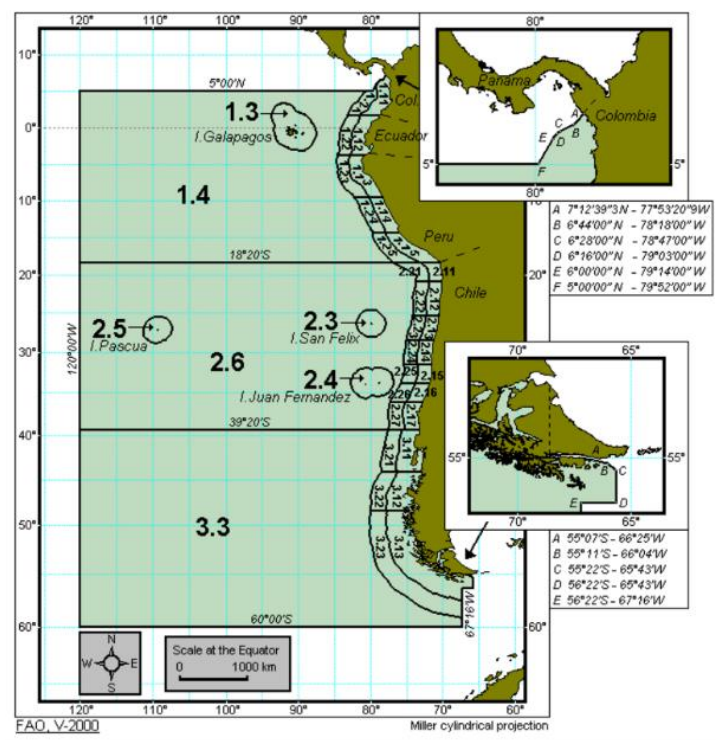

Fig. 2. Subareas of fishing area 87

The southeastern Pacific Ocean is known for its Peruvian upwelling from the fishing side. At the end of the $70 \mathrm{~s}$, the richest fishing areas were discovered here. In some years, catches here reached 11-13 million tons, mainly due to the Peruvian anchovy. Peruvian upwelling covers about 3\% of the World Ocean. Along the western shores of South America, the cold Humboldt Current passes, which carries its waters from the Antarctic; in the equator, it turns westward, lifting deep waters rich in nutrients. The most common commercial species of the fishing area is the Peruvian anchovy, of which there is a huge amount. Besides this, the area is rich in horse mackerel, mackerel, tuna, cephalopods [3].

The Peruvian anchovy is a species of fish in the anchovy family. It is considered the most numerous fish on Earth. The high number is explained by the special conditions of existence: it lives off the coast of Peru and Northern Chile, where the processes of rise to the surface of deep waters rich in nutrients (nitrogen, phosphorus, silicon) are actively taking place. As a result, a huge amount of phytoplankton develops here, which constitutes the main food of this fish species, which prefers to feed not on zooplankton, but on microscopic algae [4]. The Peruvian anchovy has no food competitors, as the coastal waters within its range are noticeably cooled compared to the neighboring areas of the open ocean. The temperature here ranges from $16-23^{\circ} \mathrm{C}$ in summer to $10-18^{\circ} \mathrm{C}$ in winter. Peruvian anchovy does not make significant migrations [3].

The number of anchovy is influenced by various climatic factors, especially susceptible to changes in water temperature. As a result of an increase in water temperature (for example, due to the penetration of tropical and subtropical water masses) in the upper 100meter layer, a spatial redistribution of commercial species occurs. Abnormal living conditions disrupt the life cycles of fish, leading to an increase in mortality, especially in the early stages of development. As a result, with an increase in water temperature, the distribution area of anchovy shifts to the coastline and is kept in about a $20-\mathrm{m}$ zone, where the temperature for its habitation is even more optimal for it. With a further increase in temperature, anchovy is distributed at the horizons of $100-150 \mathrm{~m}$, where it becomes difficult to catch it in the usual ways. There is also a shift in the distribution area to the south [5].

The rise in temperature negatively affects the mortality of eggs, larvae and fry due to the breeding conditions. This can be expressed in the direct effect of high temperature, water 
turbulence on eggs and larvae. The primary production in the region decreases due to the invasion of low-saline equatorial waters poor in nutrients. Due to changes in the feeding conditions of fish and the degree of their competition, the role of cannibalism and predation increases with an increased crowding of fish accumulations in a relatively small water area. The consequences of this determine the yield of generations of commercial fish, affecting the harvest over the next few years [6].

\section{Materials and methods}

The study examines the change in the number of anchovies depending on the climatic factor-water temperature. Data on the number of anchovies caught using the FishStat program. The relationship between the water temperature of the area and the number of anchovies is calculated using statistical methods.

The influence of climate factors on the number of anchovies was estimated by statistical methods. Studies were conducted on the series of water temperature and the number of anchovy catches for the period 1993-2019.

Correlation analysis was used to assess the existence of the relationship. To assess the tightness and direction of the relationship between variables, a correlation indicator was used. Correlation coefficient $r$, which characterizes the degree of tightness of the linear relationship

$$
r=\frac{\sum_{i=1}^{N}\left[\left(x_{1 i}-\overline{x_{1}}\right)\left(x_{2 i}-\overline{x_{2}}\right)\right]}{N \sigma_{1} \sigma_{2}}
$$

where $x_{i 1}$ and $x_{i 2}$ - the values of the first and second; $\bar{x}_{1}$ and $\overline{x_{2}}$ - he average of the first and second variables; $\sigma_{1}$ and $\sigma_{2}$ - the standard deviation of the first and second variables; $\mathrm{N}$ - the series length.

The nature of the relationship is determined by the ratio of the values of two variables. If one value increases and the other tends to increase - this is a direct relationship, then $r>0$. If one value increases and the other tends to decrease, this is an inverse relationship, then $\mathrm{r}<0$.

The significance test was carried out according to the student's criterion, the sample value was calculated using the formula:

$$
t^{*}=\frac{|r|}{\sigma_{r}}, \sigma_{r}=\frac{1-r^{2}}{\sqrt{N-2}}
$$

where $\sigma_{r}$ - the average square error of calculating the correlation coefficient.

Then the critical value is determined $t_{\kappa p}(\alpha, v)$, where is the significance level $\alpha$ accepted $5 \%$, and the number of degrees of freedom $v=N-2$, where $\mathrm{N}$ - the series length [7].

The study of the time series trend reflects the presence of a long-period fluctuation in the series with a period significantly exceeding the sample length. The linear trend equation has the form: 


$$
y=a_{1} t+a_{0}+e
$$

The trend value is equal $a_{1}$ to the linear trend coefficient. In the future, the trend should be removed from the studied series.

Physical processes can occur synchronously, but most often - asynchronously, when a change in one parameter will affect the other after some time, called a delay. The study uses cross-correlation analysis.

The calculation is made for the shift of one of the series of the coefficient of mutual correlation at each shift:

$$
r( \pm \tau)=\frac{1}{\sigma_{x} \sigma_{y}(N-1-|\tau|)} \sum_{i=1}^{N-|\tau|}\left[(x-\bar{x})\left(y_{i \pm \tau}-\bar{y}\right)\right]
$$

where $\mathrm{N}-$ the series length, $\tau$ - shift .

\section{Analysis of results}

The Peruvian anchovy, which lives in the southeastern commercial fishing zone of the Pacific Ocean, is very sensitive to fluctuations in water temperature. Anchovy develops favorably in cold waters $\left(14-18^{\circ} \mathrm{C}\right)$, which are constantly renewed by the rise of deep waters.

On the basis of the statistical analysis, we checked the effect of changes in water temperature on the anchovy catch. Fig. 3 combines the course of water temperature changes from 1993 to 2019 and the value of the anchovy catch for this period. There is a positive trend in water temperature variability (Fig. 4), i.e. From 1993 to 2019, there has been a constant increase in water temperature, at the same time, a negative trend is observed in catches of anchovy (Fig. 4), which indicates an inverse relationship between these two characteristics. A correlation coefficient of -0.29 also shows a feedback, showing that with an increase in temperature, the number of catch decreases. An increase in water temperature will lead to a decrease in the number of anchovy, therefore, to a decrease in catches, up to the complete disappearance of the species, due to the fact that this species of anchovy migrates vertically and horizontally following the movement of water masses with cold waters. During El Niño, the incoming warm water masses instead of cold ones lead to a sharp decrease in the number of the species. Figure 3 clearly shows the jumps in temperature rise in 1996-2000, 2007-2010, , from 2013 to the present. When comparing, we see that the maximum temperature rise accounts for the minimum catch, in 1997, 2010 and now. 


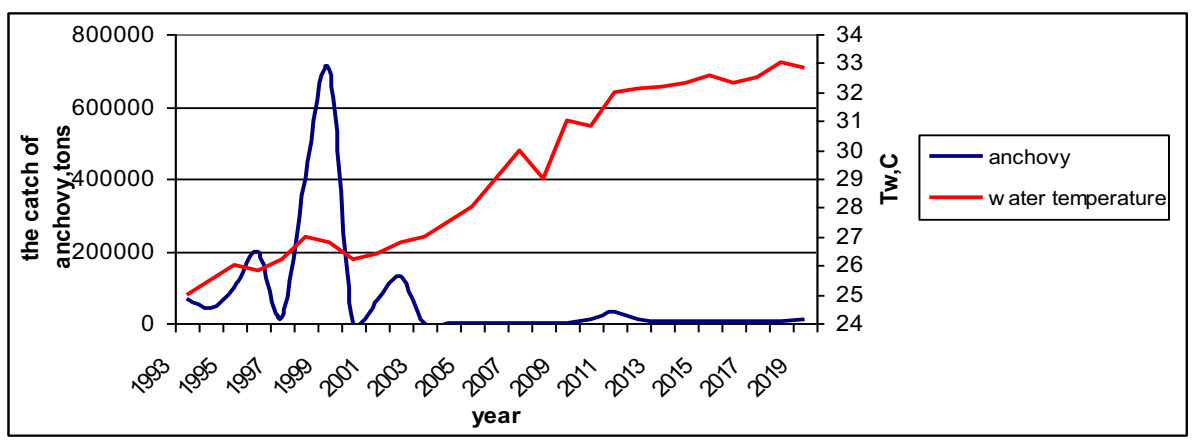

Fig. 3. Changes in the amount of anchovy caught and water temperature for the period 1993-2019

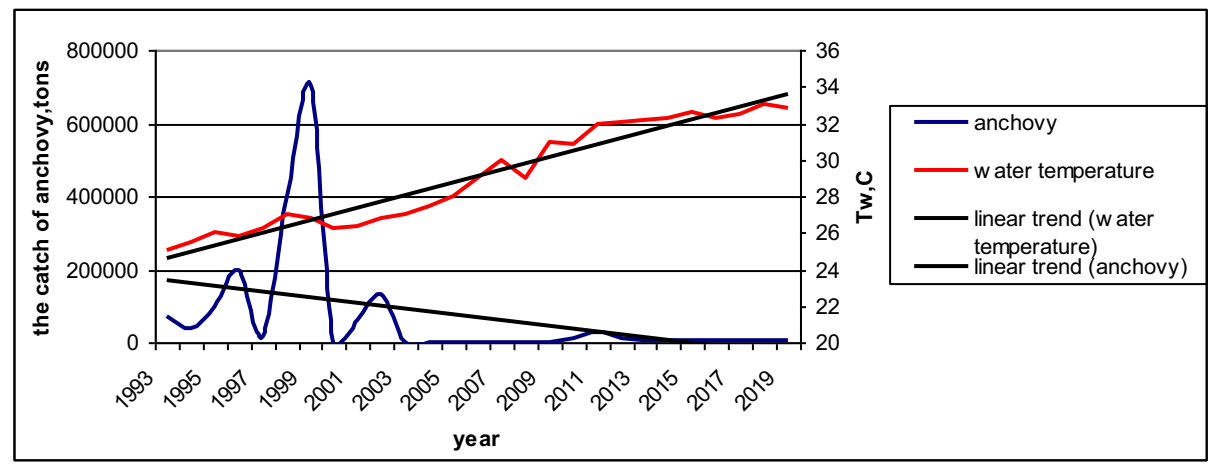

Fig. 4. Variability of water temperature and abundance of the caught anchovy with a linear trend for the period 1993-2019

The response of variability in anchovy abundance to variability in water temperature is 2 years (Fig. 5). Consequently, about 2 years after the temperature rise, there will be a jump in the decline in the number of anchovy catches. However, the correlation coefficients are not high, which suggests that a deeper analysis of the internal structure and the relationship of characteristics is required for forecasting. A significant correlation coefficient is noted at a shift of 4 years, which will make it possible to build a model for predicting anchovy abundance depending on the water temperature.

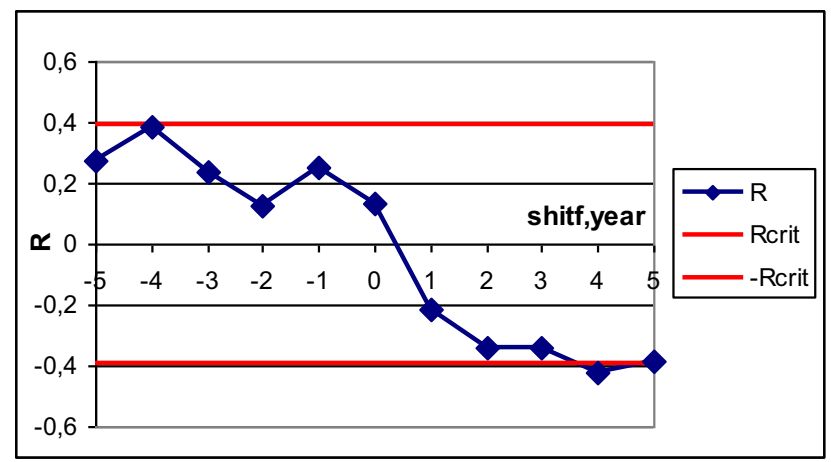

Fig. 5. Autocorrelation function 
It is also worth noting a regularity - each subsequent maximum increase in the number of anchovy is less than the previous one, except for the maximum in 1999, which suggests that with an increase in temperature, the number of anchovy decreases (Fig. 3).

\section{Conclusions}

In the course of the work, they came to the conclusion about the dependence of the anchovy population on changes in water temperature. Some scientists are talking about climate warming, according to our results, there is a positive trend, which suggests confirmation of this theory. Climate warming will negatively impact the Peruvian anchovy population and catches in the region [8].

Climate warming cannot be stopped, so new methods for assessing geo-risks should be developed [9-11] and alternative methods for preserving the Peruvian anchovy population should be sought. For example, regulate the catch of a certain type by regulating the catch at the legislative level.

\section{References}

1. L.B. Klyashtorin, A.A. Lyubushin, Cyclic climate changes and fish productivity, $\mathbf{2 3 5}$ (2005)

2. B. Bigler, D. Welch, J. Helle, Journal Fish. and Aquat. Sci., 53 (1996)

3. I. A. Martyn, Journal Processes in geoenvironments, 3(17) (2018)

4. F. Chavez, J. Ryan, S. E. Lluch-Cota, M. C. Niquen, Science, 219 (2003)

5. D. H. Cushing, N.Y.: Springer, (1978)

6. K. M. Brander, GLODEC Internal. Newsletter, 2 (2003)

7. P. M.Kilin, Statistical methods of data processing, 128 (2013)

8. I. A. Martyn, E. V. Kraeva, A. Yu. Sidorenko, Ya. A. Petrov, S. Yu. Stepanov, Information technologies and systems: management, Economics, transport, law, 4(36) (2019)

9. I. Martyn, Y. Petrov, S. Stepanov, A. Sidorenko, IOP Conference Series: Earth and Environmental Science, 539, 012198

10. E. Istomin, Y. Petrov, S. Stepanov, A. Sidorenko, I. Martyn, IOP Conference Series: Earth and Environmental Science, 507, 012006

11. A. Sidorenko, S. Stepanov, Y. Petrov, I. Martyn, IOP Conference Series: Earth and Environmental Science, 539, 012128 